\section{SARS-CoV-2 related HIV, HBV, RSV, VZV, Enteric viruses, Influenza, DENV, S. aureus and TB co-infections}

\author{
Ammara Azhar ${ }^{1}$, Umar Saeed ${ }^{2,3 *}$, Zahra Zahid Piracha ${ }^{2,3}$, Areesha \\ Amjad', Aftab Ahmed ${ }^{2}$, Syeda Itrat Batool ${ }^{1}$, Maimoona Jabeen', \\ Areej Fatima ${ }^{1}$, Fakhia Noreen ${ }^{1}$, Rehan Uppal ${ }^{2}$ and Rizwan Uppal ${ }^{2}$ \\ ${ }^{1}$ Department of Biological Sciences, International Islamic University, Islamabad, Pakistan \\ ${ }^{2}$ Department of Research and Development, Islamabad Diagnostic Center, Islamabad, Pakistan \\ ${ }^{3}$ Department of Medical Research, International Medical Research Center Islamabad, Pakistan
}

\section{Abstract}

SARS-CoV-2 a virulent disease that established the entire wide world due to its severity Its $1^{\text {st }}$ case was rumored in Wuhan, China within the year 2019 and it had been the beginning of this pandemic. This virus killed virtually a complete of $4,465,683$ folks round the globe until date. Despite the fact that viral co-infections have the ability to alter the host's illness pattern, few research have looked at the disease outcomes in patients who are infected with HIV and hCoVs. Despite the fact that HIV-positive people can be infected with hCoVs, researchers are now revealing that their chances of acquiring serious CoV-related disorders are typically similar to what is seen in the general population. The relation between SARS-CoV-2 and HBV was summarized rather HBV effects the severity of COVID patient or not. SARS-CoV-2 could be a severe acute metabolic process syndrome. Scientists found ways in which to treat this virus, some were useful and alternative weren't that a lot of effective. Immunizing agent was one among the most important considerations for the entire world. This virus conjointly fashioned an entry for alternative co-infections too. SARS-CoV-2 and influenza virus, both causes respiratory diseases which confer as an extensive array of illness from asymptomatic or benign to critical disease and death. Also the mode of transmission and symptoms of influenza virus and SARS-CoV-2 are same. Viral and bacterial rate is higher in SARS-CoV-2 negative patient but are comparable. Serologies facts confirmed that patients with effective results for dengue virus (DENV) NS1 antigen and anti-dengue IgM were also attentive to COVID-19 speedy antibody tests, suggesting dengue COVID-19 co-infection. Mixed infection of dengue and COVID-19 needs unique interest from all dengue-common nations in Asia, especially the ones with limited resources. To our knowledge, this is the primary showed case of co-infection of dengue and COVID-19 in Indonesia. During patient's TB course, COVID-19 can occur at any time with worse consequences for the patients who are affected by active pulmonary disease.
More Information

*Address for Correspondence: Dr. Umar Saeed, Department of Biological Sciences, International Islamic University, Islamabad, Pakistan, Email: umarsaeed15@yahoo.com

Submitted: September 20, 2021

Approved: November 05, 2021

Published: November 08, 2021

How to cite this article: Azhar $A$, Saeed $U$, Piracha ZZ, Amjad A, Ahmed A, et al. SARSCoV-2 related HIV, HBV, RSV, VZV, Enteric viruses, Influenza, DENV, S. aureus and TB coinfections. Arch Pathol Clin Res. 2021; 5: 026-033.

DOI: 10.29328/journal.apcr.1001025

Copyright License: (c) 2021 Azhar A, et al. This is an open access article distributed under the Creative Commons Attribution License, which permits unrestricted use, distribution, and reproduction in any medium, provided the original work is properly cited.

A) Check for updates

OPEN ACCESS

\section{Co-infection with HIV and SARS-CoV-2}

DespitethelatestdevelopmentaboutSARS-CoV-2infection, little is known about HIV infection's influence on COVID-19 [1]. In persons with HIV/acquired immunodeficiency syndrome (AIDS), frequent diseases such as lymphoma and opportunistic infections like pneumocystis pneumonia have been identified, and the immune system impairment induced by HIV often leads to the increased prevalence of SARSCoV-2 infection [2-6]. A study of HIV-positive patients found a considerably reduced number of CD4+ T cells. Considering that tissue damage in SARS-CoV-2 infection is driven by cytokine-induced cascades, [7] mortality from HIV and SARS-
CoV-2 infection are uncommon because to the deficiency of $\mathrm{CD} 4+\mathrm{T}$ cells, which prevents immune cytokine upregulation. Lympopenia has been recorded in HIV-negative COVID-19 patients; however, immune cell distribution in patients coinfected with HIV and SARS-CoV-2, as well as in patients with COVID-19 alone, differs slightly [8,9]. However, the exact impact of lymphocyte depletion in peripheral blood on the clinical outcome of HIV and SARS-CoV-2 co-infection is yet unknown [7].

SARS-CoV-2 infection is more likely in patients with AIDS, especially those with comorbidities and a high load of HIV RNA in their general circulation. The clinical signs of 
HIV and SARS-CoV-2 infection, on the other hand, are not well described $[1,10,11]$. Curiously, a lower prevalence of comorbidities, such as high blood pressure, high body mass index, diabetes, chronic liver disease, and chronic kidney disease has been documented in patients with SARS-CoV-2 or HIV infection alone compared to those with co-infection $[1,12,13]$.

Factors defining disease severity, such as lymphocyte or platelet loss, as well as higher IL-6 levels, are linked to lower CD4+ T-lymphocyte counts in HIV infection. As a result, the number of CD4+ $\mathrm{T}$ cells in patients with severe HIV and SARS-CoV-2 co-infection appears to be substantially lower than in those with mild symptoms $[1,14]$. Despite the lack of a direct link between CD4+ cells and COVID-19, immune system suppression also may contribute to disease severity, resulting in negative effects and viral infection persistence $[1]$.

A case study of a patient with combined infection of SARSCoV-2, HIV-1, and HCV suggested that a delayed antibody response could be another problem associated with such co-infection [15]. In regard to SARS-CoV-2, this denotes the impact of HIV-1 on the immune system's function [15]. However, the severity of infection with SARS-CoV-2 due to the host's impaired immune system is uncertain. Patients with severe COVID-19 had a significant decrease in the number of B and T lymphocytes, as well as natural killer (NK) cells, compared to those with mild symptoms. According to Qin, et al., the immune system function following SARS-CoV-2 infection is also reduced in the chronic phase of HIV infection, resulting in a decrease in $\mathrm{T}$ lymphocyte count [16] In addition, Suwanwongse \& Shabarek [17] reported that CD4+ T-cell dysfunction was inversely linked with clinical outcome in COVID-19 patients with HIV infection in a study of clinical symptoms in people with SARS-CoV-2/HIV co*infection [18].

Individuals with AIDS were neither immune to SARSCoV-2 nor developed a less dangerous COVID-19, according to research. Patients with low T lymphocyte numbers, on the other hand, had worse results [18]. The risk of SARS-CoV-2 infection and the severity of its clinical symptoms are greatly reduced when immunosuppressive drugs or antiviral agents, such as protease inhibitors, nucleoside reverse transduction inhibitors, or non-nucleoside reverse transduction inhibitors (NNRTIs), are given on a regular basis $[7,19,20]$.

\section{Impact of COVID-19 on HIV patients}

The coronavirus (COVID-19) pandemic is a global health emergency. It represents a significant threat for people living with HIV and AIDS, and for the global HIV response. Around 37.7 million people live with HIV worldwide. And around $27 \%$ (10.2 million) are unable to access.

HIV treatment to keep them healthy. The World Health Organization (WHO) has confirmed that people living with
HIV who catch COVID-19 are more likely to suffer severe disease and die from the coronavirus, according to a report. There is mounting evidence that the risk of death from COVID-19 among people with HIV could be as much as twice that of the general population. Coronavirus, like HIV and AIDS, has a larger impact on those who are already marginalized. As a result, poorer countries and those with higher HIV rates are our main concerns. Above all, those most affected by HIV - adolescent girls and young women, LGBT people, sex workers and people who use drugs - are feeling the effects of coronavirus more acutely [21]. Even though they appear to be very different, the SARS-CoV-2 and HIV viruses-induced disorders are very similar, they have some important points in common. Fear in the population. HIV can affect anyone, independently of their social status, race, gender, etc. This can have a psychological impact on people, causing them to feel fear, tension, or anxiety. Apart from those factors, there are others in COVID-19 that can make people feel this way: the virus is new, there are no known effective antivirals, the disease is more contagious than expected, it can even severely affect young people with no prior pathologies, respiratory failure necessitates long-term hospitalization. Both HIV and SARS-CoV-2 viruses cause an increase in cytokine production, which in the case of SARS-CoV-2 is connected to viral load. These cytokines have been linked to subsequent problems in patients who have been infected by SARS-CoV-2. Such problems include modifications of the intestinal microbiota, and Neutrophil extracellular traps (NETs) formation [22]. Common comorbidities associated with HIV/SARS-CoV-2 coinfection. CVD, cardiovascular diseases; HLD, Hyperlipidemia [4]. Because of immunological weaknesses, severe infection, and slower antibody production, co-infection with SARSCoV-2 and HIV has also been shown to be more severe [24]. Immunosuppression, as well as a weakness or failure of the humoral immune response, have all been linked to an increased risk of re-infection with SARS-CoV-2 in HIVinfected individuals. As a result, any exposure to SARS-CoV-2 in these individuals must be avoided at all costs. Following co-infection with another viral strain, studies show that the HBV virus is either reactivated or repressed. Because of the similarities of their transmission, for example, the rate of coinfection with HIV and HBV is high. In this regard, research have shown that once HIV infection suppresses the immune system, the number of antibodies associated with hepatitis $B$ decreases as a result of its reactivation, eventually leading to chronic hepatitis $B$. If a co-infection with hepatitis $C$ virus (HCV) is present, the innate immune response associated with HCV infection can also limit HBV replication [25].

\section{Effect of SARS-COV-2 on HBV infected patients}

Hepatitis and SARS-COV-2 both are extremely contagious disease which cause abnormal liver function by damaging or by failure [26]. HBV has a wide distribution globally (3.5\%), especially in China (5\% - 6\%) [27-29]. In a retrospective 
study, total 105 patient were studied with both severe diseases HBV and COVID-19 and it was observed that patient (14) with COVID-19 alone suffer from minor liver damage whereas four patients show acute-on-chronic liver failure [30]. In several studies, it was found that patient with COVID-19 alone does not cause major liver damage but varying degree of transaminase shows liver damage in patient with COVID-19 and HBV [31-37]. In COVID-19 patient liver damage is not so it can be recovered back to normal [26]. In another study, 326 corona positive patient, out of which 20 of the patients had HBV, there was no significant difference in the discharge period of two group because HBV co-infection had no effect on the course and prognosis of corona patient [31]. Furthermore, [32-35] reported that HBV co-infection does not cause disease severity such as liver damage in COVID-19 patient [26].

In case of severe corona there is high risk of HBV reactivation which is due to immunosuppressive therapy which include high-dose corticosteroids and anakinra drug $[36,37]$. Reactivation of HBV primarily means rapid increase or reappearance of HBV DNA viremia [38]. In one of the retrospective studies, it was reported that 61 patients with severe COVID-19 had high risk of HBV, after 1 month of immunosuppressive therapy no HBsAg seroconversion was found, except for two patients [39].

\section{SARS-CoV-2 and respiratory syncytial virus}

Respiratory syncytial infection (RSV), long recognized because the major microorganism infectious agent of the lower tract of newborn children, has too been entangled in extreme respiratory organ infection in grown-ups, significantly the older. This truth, and therefore the show that inactive prophylaxis with either polyclonal or organism counter acting agent to RSV avoids serious respiratory organ infection in risky newborn children and kids, has driven to reestablished intrigued inside the safe instruments encompassing security, and therefore the improvement of antibodies [40].

Respiratory Syncytial Virus (RSV) is that the most typical rationalization for respiratory illness and respiratory disorder among infants and children beneath one year oldtime. Illness begins most frequently with fever, runny nose, cough and usually asthmatic. Severe lower tract sickness might occur at any age, significantly among the older or among those with compromised internal organ, pulmonary or immune systems. RSV is unfolded from metastasis secretions through shut contact with infected persons or contact with contaminated surfaces or objects [41]. In a very traditional year, RSV causes mortality in children underneath five years old-time, leading to associate calculable 3.2 million hospital admissions and 118, 200 deaths yearly [42].

Leukocyte counts will increase due to RSV $[43,44]$. Thus, the augmented free phagocyte counts would possibly show that the patient was infected by RSV. Additionally, patients with alternative virus infection like RSV could also be a lot of prone to COVID-19 [45,46].

\section{SARS-COV-2 and Varicella herpes Virus (VZV)}

Varicella herpes virus (VZV) could be an only human virus that belongs to the $\alpha$-herpesvirus family. VZV is present worldwide and is extremely infectious. Primary infection leads to acute pox or "chickenpox", generally from exposure either through direct contact with a skin lesion or through mobile unfold from metastasis droplets $[47,48]$. Once initial infection, VZV establishes long latency in nervous and dorsal root ganglia, and will activate years to decades later as herpes (HZ) or "shingles" [49]. Over ninetieth of adults inside the non-heritable illness in childhood, whereas the bulk of children and young adults are unsusceptible with the live virus immunizing agent $[48,50]$.

Seven immunocompetent patients older than fifty years developed herpes (HZ) infection a median of nine days (range 7-20) once vaccination against SARS-CoV-2. The rumored risk and involvement of T-cell-mediated immunity recommend that vaccination with COVID-19 could be a seemingly explanation for cps. These cases support the importance of associate in progress immunizing agent safety assessment throughout the continued mass vaccination against the COVID-19 pandemic and encourage news and communication of any vaccine-related adverse events [51].

In Spain, the vaccination campaign began on January one, 2021 with the COVID-19 informational RNA BNT162b2 immunizing agent (Pfizer) four, that is primarily aimed toward older folks in nursing homes and doctors. 81.8\%) received the primary dose, throughout this era three patients came with herpes that appeared once the primary dose of the immunizing agent and a pair of once the second, all patients were young, healthy adults and their blood counts showed no abnormality [52].

\section{Enteric viral co-infections and SARS-CoV-2}

Enteric viral co-infections, infection having more than one virus that includes rotavirus, norovirus, adenovirus, enteroviruses, astrovirus etc [57]. In New York City Metropolitan area, various co-infections in SARS-CoV-2 infected patients were identified. Only less than $3 \%$ people were having co infections who were previously positive for SARS-CoV-2. Respiratory virus co infections were seen in negatively tested people including rhinovirus/Enterovirus [53]. SARS-CoV-2 positive population has a lower rate of viral co-infections compared to negatively tested population of SARS -CoV-2 [54]

Patients having SARS-CoV-2 and adenovirus co-infection experienced lymphopenia, thrombocytopenia, septic shock with having mechanical ventilator. Individuals over 15 years of age and adults were reported with the co-infection of 
Adenovirus and SARS-CoV-2 [55,59]. A study indicated that children were at more risk of developing respiratory viral co-infections as compared to the adults having SARS-CoV-2 [56]. Human rhinovirus are the most frequent respiratory viruses of the humans and causes the common cold. A study indicated that due to the rhinovirus activity, the SARS-CoV-2 replication is blocked [58].

\section{SARS-CoV-2 and influenza virus co-infection}

SARS-CoV-2 and Influenza virus co-infections were coarse during COVID-19 epidemic. SARS-CoV-2 coinfected patients along with Influenza-B virus were specified to be pretentious by low rate of serious problems in contrast with the co-infections of Influenza A virus and SARS-CoV-2 patients. Studies reveal that the SARS-CoV-2 alone or along with the Influenza Virus co-infection have almost same symptoms and vital spread. Heart diseases, diabetes, Asthma and neurological diseases were found to be common in patients having co-infection of Influenza Virus and SARSCoV-2 Infection [60]. Fever, cough, Pneumonia, fatigue, dyspnea is also seemed to be common in SARS-CoV-2 and IAV [61]. Report showed that Respiratory deterioration was rapidly developed in three out of four co-infected patients of SARS-CoV-2 and IAV [62]. SARS-CoV-2 and Influenza virus co-infection rate was as high as $57.3 \%$ of 307 COVID-19 patients in Wuhan during pandemic [63]. SARS-CoV-2 imitate the Influenza virus concerning clinical presentation, transference mechanism, and seasonal co-occurrence. So, we can say that co-infection of both viruses is comparable [60].

\section{SARS-COV-2 relation with S. aureus and other bacterial infections}

In the start of pandemic in December, 2019, when fewer number of cases were reported in Wuhan, China, it was suggested that the chances of spreading other co-infections in corona patients are rare [64]. But the data collected from the recent studies in North California, USA reveal that this rare spread of co-infection between SARS-COV-2 and respiratory viruses can each up to $21 \%$ [64]. Nasopharyngeal swab was used to test bacterial and viral co-infections [65]. Several microbiol pathogen were tested which include bacteria and viruses [65]. It was observed that the chances of bacterial and viral co-infection are notably higher in SARS-COV-2 negative (35\%) than in SARS-COV-2 positive (33\%) but was comparable [66]. A complete examination of co-infecting pathogen includes $S$. aureus, K. pneumoniae, S. pneumoniae, $H$. influenzae which were the most prevailing bacterial coinfections in SARS-COV-2 positive as well as SARS-COV-2 negative population [66]. This rate was higher in SARS-COV-2 negative patient with the exception of $S$. aureus which was opposite of the other obtained result [66]. Staphylococcus aureus is the most hazardous of the entirety of the numerous normal staphylococcal microscopic organisms [67]. These gram-positive, circle molded (coccal) microscopic organisms frequently cause skin diseases yet can cause pneumonia, heart valve contaminations, and bone contaminations [67]. Viral co-infection showed similar trend [68]. Other than EBV all the viral infection showed less than $1 \%$ incident rate [66]. Moreover, potential clarification for the lower viral co-disease rate could be the time period wherein the investigation was led [66]. Comparable examination has been reported with respect to higher EBV co-infections in COVID-19 patients in Wuhan, China [69]. Also, SARS-CoV-2 has been involved in the reactivation of a few herpesviruses, including varicella zoster virus (human herpesvirus 3; HHV3), Epstein-Barr infection (HHV4) and roseolo-virus (HHV6, HHV7) [70,71].

\section{SARS-CoV-2 co-infection with DENV}

One of the highest possible public health issues in Asian nations is DENV [72]. More common in rainy seasons, causing situations varying from mild dengue fever (DF) to severe hemorrhagic DF and dengue shock syndrome $[73,74]$. High-grade fever and flu-like signs and symptoms are the most important clinical analytical manifestations of both DENV disease and COVID-19, and the similarity of these signs and symptoms can increase the risk of misdiagnosis. A research carried out by 9 [75] recommended the opportunity of DENV and SARS-CoV-2 co-infection, characterized by extended fever. Similarly, in Thailand, [76,77] suggested blended infection of DENV and SARS-CoV-2, characterized by petechial rash, and breathing signs and symptoms as a result of COVID-19.

In this respect, it turned into concept that patients with fever could be co-infected with SARS- CoV-2 and DENV, a condition most common in areas, including Singapore, Thailand, Malaysia in South-east Asia, and Brazil in South America. In terms of clinical symptoms, $87.9 \%$ of COVID-19 patients presented with fever, $67.7 \%$ reported cough and $13.7 \%$ complained of headache. On the comparison, all patients with DENV infection had fever, whereas only $25.7 \%$ reported headache $[78,79]$. Serious breathing signs and symptoms were not found in individuals with either SARSCoV-2 or DENV infection or co-infection [80].

Cases with no report of DENV-related signs and symptoms, co-infection with SARS-CoV-2 might result in the worsening of breathing complications, mandating hospitalization. Although the number of lymphocytes and monocytes can lower in co-infection with SARS-CoV-2 and DENV, leukopenia has only been documented in patients with classic DF [81]. It needs to be cited that co-infection with SARS-CoV-2 and DENV are with improved blood glucose levels, which favor replication of SARS-CoV-2 [82]. Bleeding issues had been diagnosed in a few cases during COVID-19. The most frequent sign of DF is bleeding, which might worsen the infection [83]. Lymphopenia has been known to contribute to bleeding in the presence of SARS-CoV-2 and DF infection alone; therefore, the ratio of neutrophils to lymphocytes in DENV infection can become inverse [85]. Accordingly, this process might have a significant effect on the development of DF and its natural history [86]. 
Two clear cases of co-infection were mentioned formerly in Reunion Island [87] and in Mayotte [88] in France. Nevertheless, possible co-infection was also discovered in Asia [89]. A study in Bangladesh discovered that co-infection happened among 4 out of 20 patients, and co-infection was related to a high mortality rate [90]. A co-infection of SARSCoV-2 and DENV has not been properly studied. It is doubtful if it could coexist with DENV in the identical person affected individual, as it was assumed that DENV could block the entry of another virus in the same host cell [91].

\section{Interaction between SARS-CoV-2 and TB}

Infectious diseases like COVID-19 and TB generally affect the lungs. TB spread through infectious droplet; SARS-COV-2 spread out through aerosol [92]. Significant modifications have caused in TB care by COVID-19 pandemic. During the COVID-19 pandemic TB sufferers showed more prolonged pulmonary forms. The increase in TB infection and presence of TB in the kids of affected person can increased transmission because anti COVID-19 cautions [93]. Both of the disease is propagated by the overcrowding $[94,95]$. Medical appearance is concerned, as symptoms like fever, cough, weakness, malaise and hemoptysis may be same in both conditions. Same displays can posture a diagnostic challenge [96]. Basing on immunological mechanism Involved, a not unusual place dysregulation of immune responses in COVID-19 has been found, indicating a double threat Posed by co-infection, worsening COVID-19 rigorousness and assisting TB disorder advancement/progression [97]. Host immune responses are deteriorated/impair by other viral respiratory infection TB but a bit proof is accessible about co-infection of SARSCOV-2 and Mycobacterium tuberculosis. By acknowledging a case studied in India and China, TB status may play a part in improvement of COVID-19 infection and worsening of the course of the disease for the co-infected population [98]. The proof given by study, accomplish on a systematic transcriptomic interpretation/evaluation of immune signature related with COVID-19 clinical extremity, and the spectrum of asymptomatic and symptomatic TB. In fact the conclusion of this study accomplish on the transcriptomic evaluation on peripheral blood mononuclear cell (PBMC), Whole blood (WB), and Broncho alveolar lavage fluid (BALF) signature commend that impair and active TB (ATB) added the risk of intense COVID-19 disease due to plenty of circulating myeloid subpopulations which are also present in the lungs of impetuous COVID-19 sufferers [99]. In both severe disease in COVID-19 and TB, the increased production of IFN and the type 1 and III IFN responses are notably upregulated $[100,101]$. In impetuous and critic COVID-19 patients the use of immunosuppressive drugs although it is used for a small duration but it may lead to increased tendency of active TB because of reactivation or new infection if Mycobacterium tuberculosis even in post- pandemic era [102,103]. The TB dominancy was higher in between COVID-19 sufferers ranged from $0.47 \%$ to $4.47 \%$. The TB dominancy became better in the COVID-19 patients with severe COVID-19 than in non-intense ones 1.47\%, 10/680 vs. 0.59\%, 10/1703; OR: $2.1 ; p=0.24$ [104]. During patient's TB course, COVID-19 can occur at any time with worse consequences for the patients who are affected by active pulmonary disease [97].

\section{Conclusion}

COVID-19 is a dangerous condition, and all people living with HIV should take all advised precautions to limit their exposure to the virus that causes COVID-19 and prevent infection. People living with HIV who are older or who have heart or lung difficulties are at a higher risk of becoming infected with the virus and developing more serious symptoms, just like the general population. HBV does not affect the condition of patient with covid-19. Minor damage occur which is recovered. Although, in severe condition reactivation of HBV occurs. This file verifies that, in pandemic era, diagnosing one infection does not rule out the opportunity having any another infection concomitantly. The use of immunosuppressive drugs COVID-19 may cause increased tendency of active TB due to reactivation or new infection if Mycobacterium tuberculosis. In addition, it underscores the significance of correct and timely diagnosis, with a entire laboratory research for both dengue and COVID-19, in territories where there is a possibility of dengue infection, since each infection has distinctive medical management. Beyond that, we alert for this public health concern, especially highlighting the need in acquiring the proper contact and droplet precautions in health services and communities, helping decreasing human-to-human transmission, prevent outbreaks and put off the spread of COVID-19 pandemic.

\section{References}

1. Vizcarra P, Pérez-Elías MJ, Quereda C, Moreno A, Vivancos MJ, et al. Description of COVID-19 in HIV-infected individuals: a singlecentre, prospective cohort. Lancet HIV. 2020; 7: 554-564. PubMed: https://pubmed.ncbi.nlm.nih.gov/32473657/

2. Zhang JC, Zhang HJ, Li Y, Jing D, Liu Q, et al. Changes in levels of $T$ cell subpopulations to monitor the response to antiretroviral therapy among HIV-1-infected patients during two years of HIV-1 replication suppression. Scand J Infect Dis. 2013; 45: 368-377.

PubMed: https://pubmed.ncbi.nIm.nih.gov/23186319/

3. Chen G, Wu D, Guo W, Cao Y, Huang D, et al. Clinical and immunological features of severe and moderate coronavirus disease 2019. J Clin Invest. 2020; 130: 2620-2629.

PubMed: https://pubmed.ncbi.nlm.nih.gov/32217835/

4. Kanwugu ON, Adadi P. HIV/SARS-CoV-2 co-infection: a global perspective. J Med Virol. 2020; 93: 726-732.

PubMed: https://pubmed.ncbi.nlm.nih.gov/32692406/

5. GuoW, Ming F, Feng Y, Zhang Q, MoP, etal. Patterns of HIV and SARSCoV-2 co-infection in Wuhan, China. J Int AIDS Soc. 2020; 23:25568. PubMed: https://pubmed.ncbi.nlm.nih.gov/32697865/

6. Jiang $\mathrm{H}$, Zhou $\mathrm{Y}$, Tang W. Maintaining HIV care during the COVID-19 pandemic. The Lancet HIV. 2020; 7: e308-e309.

PubMed: https://pubmed.ncbi.nlm.nih.gov/32272084/

7. Guo W, Ming F, Yu D. A survey for COVID-19 among HIVIAIDS patients in two Districts of Wuhan, China, 2020. 
8. Bai $Y$, Yao L, Wei T, Tian F, Jin DY, et al. Presumed asymptomatic carrier transmission of COVID-19. JAMA. 2020; 323: 1406-1407. PubMed: https://pubmed.ncbi.nlm.nih.gov/32083643/

9. Wang $\mathrm{F}$, Nie J, Wang $\mathrm{H}$, Zhao $\mathrm{Q}$, Xiong $\mathrm{Y}$, et al. Characteristics of peripheral lymphocyte subset alteration in COVID-19 pneumonia. J Infect Dis. 2020; 221: 1762-1769.

PubMed: https://pubmed.ncbi.nlm.nih.gov/32227123/

10. Zhu F, Cao Y, Xu S, Zhou M. Reply to Comments on 'Co-infection of SARS-CoV-2 and HIV in a patient in Wuhan city, China'. J Med Virol. 2020; 92: 1417-1418.

PubMed: https://pubmed.ncbi.nlm.nih.gov/32266995/

11. Zhu F, Cao Y, Xu S, Zhou M. Co-infection of SARS-CoV-2 and HIV in a patient in Wuhan city, China. J Med Virol. 2020; 92: 529-530. PubMed: https://pubmed.ncbi.nlm.nih.gov/32160316/

12. Jiehao $C$, Jin $X$, Daojiong L, Zhi Y, Lei X, et al. A Case Series of children with 2019 novel coronavirus infection: clinical and epidemiological features. Clin Infect Dis. 2020; 71: 1547-1551

PubMed: https://pubmed.ncbi.nlm.nih.gov/32112072/

13. Yan S, Song $X$, Lin F. Clinical characteristics of coronavirus disease 2019 in Hainan, China. medRxiv. 2020.

14. Liu B, Li M, Zhou Z, Guan X, Xiang Y. Can we use interleukin-6 (IL-6) blockade for coronavirus disease 2019 (COVID-19)-induced cytokine release syndrome (CRS)? J Autoimmun. 2020; 111: 102452. PubMed: https://pubmed.ncbi.nlm.nih.gov/32291137/

15. Zhao J, Liao X, Wang H, Wei L, Xing M, et al. Early virus clearance and delayed antibody response in a case of COVID-19 with a history of coinfection with HIV-1 and HCV. Clin Infect Dis. 2020; 71: 2233-2235. PubMed: https://pubmed.ncbi.nlm.nih.gov/32270178/

16. Qin C, Zhou L, Hu Z, Zhang S, Yang S, et al. Dysregulation of immune response in patients with COVID-19 in Wuhan, China. Clin Infect Dis. 2020; 71: 762-768.

PubMed: https://pubmed.ncbi.nlm.nih.gov/32161940/

17. Suwanwongse K, Shabarek N. Clinical features and outcome of HIV/ SARS-CoV-2 co-infected patients in the Bronx, New York City. J Med Virol. 2020; 92: 2387-2389.

PubMed: https://pubmed.ncbi.nlm.nih.gov/32462663/

18. Maggiolo F, Zoboli F, Arosio M, Valenti D, Guarneri D, et al. SARSCoV-2 infection in persons living with HIV: a single center prospective cohort. J Med Virol. 2020; 93: 1145-149.

PubMed: https://pubmed.ncbi.nlm.nih.gov/32706409/

19. Park SY, Lee JS, Son JS, Ko JH, Peck KR, et al. Post-exposure prophylaxis for Middle East respiratory syndrome in healthcare workers. J Hosp Infect. 2019; 101: 42-46.

PubMed: https://pubmed.ncbi.nlm.nih.gov/30240813/

20. Joob B, Wiwanitkit V. SARS-CoV-2 and HIV. J Med Virol. 2020; 92: 1415.

PubMed: https://pubmed.ncbi.nlm.nih.gov/32220066/

21. Xia Y, Protzer U. Control of hepatitis $B$ virus by cytokines. Viruses. 2017; 9: 18.

PubMed: https://pubmed.ncbi.nlm.nih.gov/28117695/

22. World Health Organization (WHO), 2021.

23. Wang $M, W u Q, X u W$, et al. Clinical diagnosis of 8274 samples with 2019-novel coronavirus in Wuhan. medRxiv. 2020.

24. Chen X, Liao B, Cheng L, et al. The microbial co-infection in COVID-19. Appl Microbiol Biotechnol. 2020; 104: 7777-7785.

25. Li, Y, Xia, L. Coronavirus disease 2019 (COVID-19): role of chest CT in diagnosis and management. Am J Roentgenol. 2020; 214:1280-1286. PubMed: https://pubmed.ncbi.nlm.nih.gov/32130038/

26. Chen L, Huang S, Yang J, Cheng $X$, Shang $Z$, et al. Clinical characteristics in patients with SARS-CoV-2/HBV co-infection. J Viral
Hepatitis. 2020; 27: 1504-1507

PubMed: https://pubmed.ncbi.nlm.nih.gov/32668494/

27. Chen X, Jiang Q, Ma Z, Ling J, Hu W, et al. Clinical Characteristics of Hospitalized Patients with SARS-CoV-2 and Hepatitis B Virus Coinfection. Virologica Sinica. 2020; 35: 842-845.

PubMed: https://pubmed.ncbi.nlm.nih.gov/32839868/

28. Li Y, Li C, Wang J, Zhu C, Zhu L, et al. A case series of COVID-19 patients with chronic hepatitis B virus infection. J Med Virol. 2020; 92: 2785-2791.

PubMed: https://pubmed.ncbi.nlm.nih.gov/32558945/

29. Jiaye L, Wang T, Cai Q, Sun L, Huang D, et al. Longitudinal changes of liver function and hepatitis B reactivation in COVID-19 patients with pre-existing chronic hepatitis B virus infection. Hepatol Res. 2020; 50 : 1211-1221.

PubMed: https://pubmed.ncbi.nlm.nih.gov/32761993/

30. Jue L, Zhang S, Wang Q, Shen H, Zhang M, et al. Seroepidemiology of hepatitis $B$ virus infection in 2 million men aged 21-49 years in rural China: a population-based, cross-sectional study. Lancet Infect Dis. 2016; 16: 80-86.

PubMed: https://pubmed.ncbi.nlm.nih.gov/26268687/

31. Loomba R, Liang TJ. Hepatitis B Reactivation Associated With Immune Suppressive and Biological Modifier Therapies: Current Concepts, Management Strategies, and Future Directions. Gastroenterology. 2018; 152: 1297-1309.

PubMed: https://pubmed.ncbi.nlm.nih.gov/28219691/

32. Rodríguez-Tajes S, MiralpeixA, Costa J, López-SuñéE, Laguno M, etal. Low risk of hepatitis $B$ reactivation in patients with severe COVID-19 who receive immunosuppressive therapy. J Viral Hepat. 2021; 28: 89-94. PubMed: https://pubmed.ncbi.nlm.nih.gov/32969557/

33. Shi $Y$, Zheng $M$. Hepatitis $B$ virus persistence and reactivation. The BMJ. 2020; 370

PubMed: https://pubmed.ncbi.nlm.nih.gov/32873599/

34. Since January 2020 Elsevier has created a COVID-19 resource centre with free information in English and Mandarin on the novel coronavirus COVID-19. The COVID-19 resource centre is hosted on Elsevier Connect, the company 's public news and information. 2020.

35. Sonneveld MJ, Murad SD, van der Eijk AA, de Man RA. Fulminant Liver Failure due to Hepatitis B Reactivation During Treatment With Tocilizumab. ACG Case Rep J. 2019; 6: e00243. PubMed: https://pubmed.ncbi.nlm.nih.gov/32042838/

36. Soriano CV. No Title No Title No Title. GEPCOMM Diagnostic Essay, 2021.

37. Wong GLH, Wong VWS, Yuen BWY, Tse YK, Yip TCF, et al. Risk of hepatitis B surface antigen seroreversion after corticosteroid treatment in patients with previous hepatitis B virus exposure. J Hepatol. 2020; 72: 57-66.

PubMed: https://pubmed.ncbi.nlm.nih.gov/31499132/

38. Xiang TD, Zheng X. Interaction between hepatitis $B$ virus and SARS-CoV-2 infections. World J Gastroenterol. 2021; 27: 782-793. PubMed: https://pubmed.ncbi.nlm.nih.gov/33727770/

39. Yuen MF, Chen DS, Dusheiko GM, Janssen HLA, Lau DTY, et al. Hepatitis B virus infection. Nat Rev Dis Primers. 2018; 4: 18035.

40. https://doi.org/10.1016/S0140-6736(99)80040-3

41. https://www.certest.es/products/sars-cov-2-flu-a-flu-b-rsv/

42. Shi T, McAllister DA, O'Brien KL, Simoes EAF, Madhi SA, et al. Global, regional, and national disease burden estimates of acute lower respiratory infections due to respiratory syncytial virus in young children in 2015: a systematic review and modelling study. Lancet. 2017; 390: 946-958

PubMed: https://pubmed.ncbi.nlm.nih.gov/28689664/

43. Oray-Schrom P, Phoenix C, St Martin D, Amoateng-Adjepong Y. 
Sepsis workup in febrile infants 0-90 days of age with respiratory syncytial virus infection. Pediatr Emerg Care. 2003; 19: 314-319. PubMed: https://pubmed.ncbi.nlm.nih.gov/14578830/

44. Zhang X, Chen Z, Gu W, Ji W, Wang Y, et al. Viral and bacterial co-infection in hospitalized children with refractory Mycoplasma pneumoniae pneumonia. Epidemiol Infect. 2018; 146: 1384-1388. PubMed: https://pubmed.ncbi.nlm.nih.gov/29970200/

45. Hageman JR. The coronavirus disease 2019 (COVID-19). Pediatr Ann. 2020; 49: e99-e100

PubMed: https://pubmed.ncbi.nlm.nih.gov/32155273/

46. Li Y, Xia L. Coronavirus disease 2019 (COVID-19): role of chest CT in diagnosis and management. Am J Roentgenol. 2020; 214: 1280-1286. PubMed: https://pubmed.ncbi.nlm.nih.gov/32130038/

47. Sawyer MH, Chamberlin CJ, Wu YN, Aintablian N, Wallace MR. Detection of varicella -zoster virus DNA in air samples from hospital rooms. J Infect Dis. 1994; 169: 91-94.

48. Gnann JW, Jr, Whitley RJ. Clinical practice. Herpes zoster. N Engl J Med. 2002; 347: 340-346.

PubMed: https://pubmed.ncbi.nlm.nih.gov/23863052/

49. Gilden DH, Kleinschmidt-DeMasters BK, LaGuardia JJ, Mahalingam $\mathrm{R}$, Cohrs RJ. Neurologic complications of the reactivation of varicellazoster virus. N Engl J Med. 2000; 342: 635-645.

PubMed: https://pubmed.ncbi.nlm.nih.gov/10699164/

50. Marin M, Guris D, Chaves SS, Schmid S, Seward JF. Prevention of varicella: recommendations of the Advisory Committee on Immunization Practices (ACIP). MMWR Recomm Rep. 2007; 56: 1-40.

51. Psichogiou M. Samarkos M. Mikos N. Hatzakis A. Reactivation of Varicella Zoster Virus after Vaccination for SARS-CoV-2. Vaccines. 2021; 9: 572

PubMed: https://pubmed.ncbi.nlm.nih.gov/34205861/

52. Polack FP, Thomas SJ, Kitchin N. Safety and efficacy of the BNT162b2 mRNA Covid-19 vaccine. N Engl J Med. 2020; 383: 2603-2615.

53. https://doi.org/10.1016/j.jdcr.2021.04.014

54. Nowak MD, Sordillo EM, Gitman MR, Mondolfi AEP

55. Singh V, Upadhyay P, Reddy J, Granger J. SARS-CoV-2 respiratory co-infections: Incidence of viral and bacterial co-pathogens. Int J Infect Dis. 2021; 105: 617-620.

56. Pigny F, Wagner N, Rohr M, Mamin A, Cherpillod P, et al. Geneva Pediatric COVID Group

57. Makimaa $H$, Ingle $H$, Baldridge $M T$.

58. Dee K, Goldfarb DM, Haney J, Amat JAR, Herder V, et al.

59. Aghbash PS, Eslami N, Shirvaliloo M, Baghi HB. First published: 25 May 2021.

60. WHO Coronavirus disease 2019 (COVID-19) situation report-100. 2020.https://www.who.int/docs/default-source/coronaviruse/situationreports/20200429-sitrep-100-covid-19.pdf?sfvrsn=bbfbf3d1 6

61. Huang C. Wang Y, Li X, Ren L, Zhao J, et al. Clinical features of patients infected with 2019 novel coronavirus in Wuhan, China. Lancet. 2020; 395: 497-506.

PubMed: https://pubmed.ncbi.nlm.nih.gov/31986264/

62. Cuadrado-Payán E, Montagud-Marrahi E, Torres-Elorza M, Bodro M, Blasco M, et al. SARS-CoV-2 and influenza virus co-infection. Lancet. 2020; 395: e84.

PubMed: https://pubmed.ncbi.nlm.nih.gov/32423586/

63. Yue $\mathrm{H}$, Zhang $\mathrm{M}$, Xing L, Wang $\mathrm{K}$, Rao X, et al. The epidemiology and clinical characteristics of co-infection of SARS-CoV-2 and influenza viruses in patients during COVID-19 outbreak. J Med Virol. 2020; 92: 2870-2873.

PubMed: https://pubmed.ncbi.nlm.nih.gov/32530499/
64. Kim KW, Deveson IW, Pang CNI, Yeang M, Naing Z, et al. Respiratory viral co-infections among SARS-CoV-2 cases confirmed by virome capture sequencing. Sci Rep. 2021; 11: 34-39. PubMed: https://pubmed.ncbi.nlm.nih.gov/33594223/

65. Reddy J, Singh V, Granger J. A Survey of Viral-bacterial Co-infection in Respiratory Samples Using Multiplex Real Time-PCR. 2019.

66. Singh V, Upadhyay P, Reddy J, Granger J. SARS-CoV-2 respiratory co-infections: Incidence of viral and bacterial co-pathogens. Int $J$ Infect Dis. 2021; 105: 617-620.

PubMed: https://pubmed.ncbi.nlm.nih.gov/33640570/

67. Mulcahy ME, McLoughlin RM. Staphylococcus aureus and influenza a virus: Partners in co-infection. M Bio. 2016; 7: e02068-16. PubMed: https://www.ncbi.nlm.nih.gov/pmc/articles/PMC5156308/

68. Kim D, Quinn J, Pinsky B, Shah NH, Brown I. Rates of Co-infection between SARS-CoV-2 and Other Respiratory Pathogens. JAMA. 2020; 323: 2085-2086.

PubMed: https://pubmed.ncbi.nlm.nih.gov/32293646/

69. Chen T, Song J, Liu H, Zheng H, Chen C. Positive Epstein-Barr virus detection in coronavirus disease 2019 (COVID-19) patients. Sci Rep. 2021; 11: 10902

PubMed: https://pubmed.ncbi.nlm.nih.gov/34035353/

70. Massey BW, Jayathilake K, Meltzer HY. Respiratory Microbial Co-infection With SARS-CoV-2. Front Microbiol. 2020; 11: 2079. PubMed: https://www.ncbi.nlm.nih.gov/pmc/articles/PMC7477285/

71. Ciccarese G, Parodi A, Drago F. SARS-CoV-2 as possible inducer of viral reactivations. Dermatol Ther. 2020; 33; e13878. PubMed: https://pubmed.ncbi.nlm.nih.gov/32558172/

72. Xu L, Liu J, Lu M, Yang D, Zheng X. Liver injury during highly pathogenic human coronavirus infections. Liver Int. 2020; 40: 998-1004. PubMed: https://pubmed.ncbi.nlm.nih.gov/32170806/

73. Xu L, Liu J, Lu M, Yang D, Zheng X. Liver injury during highly pathogenic human coronavirus infections. Liver Int. 2020; 40: 998-1004. PubMed: https://pubmed.ncbi.nlm.nih.gov/32170806/

74. Halstead SB. Dengue. The Lancet. 2007; 370: 1644-1652. PubMed: https://pubmed.ncbi.nlm.nih.gov/17993365/

75. Setiati TE, Wagenaar JFP, de Kruif M, Mairuhu A. Changing epidemiology of dengue haemorrhagic fever in Indonesia. Dengue Bull. 2006; 30: 1-14.

76. Yan G, Lee CK, Lam L, Yan B, Chua YX, et al. Covert COVID-19 and false-positive dengue serology in Singapore. Lancet Infect Dis. 2020; 20: 536.

PubMed: https://pubmed.ncbi.nlm.nih.gov/32145189/

77. Yan G, LeeCK, LamL, YanB, ChuaYX, etal. CovertCOVID-19andfalsepositive dengue serology in Singapore. Lancet Infect Dis. 2020; 20: 536. PubMed: https://pubmed.ncbi.nlm.nih.gov/32145189/

78. Joob B, Wiwanitkit V. COVID-19 can present with a rash and be mistaken for Dengue. J Am Acad Dermatol. 2020; 82: e177. PubMed: https://pubmed.ncbi.nlm.nih.gov/32213305/

79. Guan WJ, Ni ZY, Hu Y, et al. Clinical characteristics of coronavirus disease 2019 in China. N Engl J Med. 2020; 382: 1708-1720.

80. Chen D, Zhang $\mathrm{Y}, \mathrm{Wu} \mathrm{X}, \mathrm{Wu} \mathrm{J}$, Gong F, et al. A survey of clinical and laboratory characteristics of dengue fever epidemic from 2014 to 2018 in Guangzhou, China. Ann Palliative Med. 2020; 9: 70-81. PubMed: https://pubmed.ncbi.nlm.nih.gov/32005065/

81. Bicudo N, Bicudo E, Costa JD, Castro J, Barra GB. Co-infection of SARS-CoV-2 and dengue virus: a clinical challenge. Braz J Infect Dis. 2020; 24: 452-454.

PubMed: https://pubmed.ncbi.nlm.nih.gov/32866435/

82. Saddique A, Rana MS, Alam MM, Ikram A, Usman M, et al. Emergence of co-infection of COVID-19 and dengue: a serious public health threat. J Infect. 2020; 81: 16-18.

PubMed: https://pubmed.ncbi.nlm.nih.gov/32800797/ 
83. Codo AC, Davanzo GG, Monteiro LB, de Souza GF, Muraro SP, et al. Elevated glucose levels favor SARS-CoV-2 infection and monocyte response through a HIF-1a/glycolysis-dependent axis. Cell Metab. 2020; 32: 437-446e5.

PubMed: https://pubmed.ncbi.nlm.nih.gov/32697943/

84. Al-Samkari H, Karp Leaf RS, Dzik WH, Carlson JCT, Fogerty AE, et al. COVID-19 and coagulation: bleeding and thrombotic manifestations of SARS-CoV-2 infection. Blood. 2020; 136: 489-500.

PubMed: https://pubmed.ncbi.nlm.nih.gov/32492712/

85. Imad HA, Phumratanaprapin W, Phonrat B, Chotivanich K, Charunwatthana $\mathrm{P}$, et al. Cytokine expression in dengue fever and dengue hemorrhagic fever patients with bleeding and severe hepatitis. Am J Trop Med Hyg. 2020; 102: 943-950.

PubMed: https://pubmed.ncbi.nlm.nih.gov/32124729/

86. Hilmy AI, Dey RK, Imad HA, Yoosuf AN, Latheef AA, et al. Coronavirus disease 2019 and dengue: two case reports. J Med Case Rep. 2021; 15: $171-177$

87. Verduyn M, Allou N, Gazaille V, Andre M, Desroche T, et al. Coinfection of dengue and COVID-19: a case report. PLoS Negl Trop Dis. 2020; 14: e0008476.

PubMed: https://www.ncbi.nlm.nih.gov/pmc/articles/PMC7398491/

88. EpelboinL,BlondeR,NacherM,CombeP,ColletL.COVID-19anddengue co-infection in a returning traveller. J Travel Med. 2020; 27: taaa114. PubMed: https://pubmed.ncbi.nlm.nih.gov/32657339/

89. Miah MA, Husna A. Co-infection, coepidemics of COVID-19, and dengue in dengueendemic countries: a serious health concern. J Med Virol. 2020; 93: 161-162.

PubMed: https://pubmed.ncbi.nlm.nih.gov/32633829/

90. Saddique A, Rana MS, Alam MM, Ikram A, Usman M, Salman M, et al. Emergence of co-infection of COVID-19 and dengue: a serious public health threat. J Infect. 2020; 81: e16-e18.

PubMed: https://pubmed.ncbi.nlm.nih.gov/32800797/

91. Pinky L, Dobrovolny HM. Co-infections of the respiratory tract: viral competition for resources. PLoS One. 2016, 11: e0155589. PubMed: https://pubmed.ncbi.nlm.nih.gov/27196110/

92. Jayaweera M, Perera H, Gunawardana B, Manatunge J. Transmission of COVID-19 virus by droplets and aerosols: a critical review on the unresolved dichotomy. Environ Res. 2020; 188: 109819. PubMed: https://pubmed.ncbi.nlm.nih.gov/32569870/

93. Impact of the COVID-19 pandemic on tuberculosis management in
Spain ML Aznar J. Espinosa-Pereiro N. Saborit R. Zules I. Molina Adrián Sánchez-Montalvá. 2021.

94. Srivastava K, Kant S, Verma A. Role of environmental factors in transmission of tuberculosis. DHH. 2015; 2: 12.

95. Ge H, Wang X, Yuan X, Xiao G, Wang C, et al. The epidemiology and clinical information about COVID-19. Eur J Clin Microbiol Infect Dis. 2020; 39: 1011-1019.

PubMed: https://pubmed.ncbi.nlm.nih.gov/32291542/

96. Tadolini M, Codecasa LR, García-García JM, et al. Active tuberculosis, sequelae and COVID-19 co-infection: first cohort of 49 cases. Eur Respir J. 2020; 56: 2001398.

PubMed: https://pubmed.ncbi.nlm.nih.gov/32457198/

97. Visca D, Ong CWN, Tiberi S, Centis R. D'Ambrosioh B. et al. Tuberculosis and COVID-19 interaction: A review of biological, clinical and public health effects. Pulmonology. 2021; 27: 151-165. PubMed: https://pubmed.ncbi.nlm.nih.gov/33547029/

98. Yasri S, Wiwanitkit V. Tuberculosis and novel Wuhan coronavirus infection: Pathological interrelationship. Indian J Tuberc. 2020; 67: 264. PubMed: https://pubmed.ncbi.nlm.nih.gov/32553324/

99. Sheerin D, Abhimanyu WX, Johnson WE, Coussens A. Systematic evaluation of transcriptomic disease risk and diagnostic biomarker overlap between COVID-19 and tuberculosis: a patient-level metaanalysis. MedRxiv. 2020; 20236646.

PubMed: https://pubmed.ncbi.nlm.nih.gov/33269371/

100. Acharya D, Liu G, Gack MU. Dysregulation of type I interferon responses in COVID-19. Nat Rev Immunol. 2020; 20: 397-398. PubMed: https://pubmed.ncbi.nlm.nih.gov/32457522/

101. Cliff JM, Kaufmann SHE, McShane H, van Helden P, O'Garra A. The human immune response to tuberculosis and its treatment: a view from the blood. Immunol Rev. 2015; 264: 88-102.

PubMed: https://pubmed.ncbi.nlm.nih.gov/25703554/

102. Yang H, Lu S. COVID-19 and Tuberculosis. J TransI Int Med. 2020; 8: 59-65.

PubMed: https://pubmed.ncbi.nlm.nih.gov/32983927/

103. Minozzi S, Bonovas S, Lytras T, Pecoraro V, González-Lorenzo M, et al. Risk of infections using anti-TNF agents in rheumatoid arthritis, psoriatic arthritis, and ankylosing spondylitis: a systematic review and meta-analysis. Expert Opin Drug Saf. 2016; 15: 11-34. PubMed: https://pubmed.ncbi.nlm.nih.gov/27924643/ 